\title{
Effect of Plasticizer on Delivery of Valsartan from Tamarind Gel Based Transdermal Film Formulation
}

\author{
Braja Bihari Panda1, Ayan Chatterjee', Rudra Narayan Sahoo ${ }^{1,2}$, Subrata Mallick ${ }^{1, *}$ \\ 'School of Pharmaceutical Sciences, Siksha 'O' Anusandhan (Deemed to be University), Bhubaneshwar, Odisha, INDIA. \\ ${ }^{2}$ School of Pharmacy and Life Sciences, Centurion University of Technology and Management, Bhubaneswar, Odisha, INDIA.
}

\begin{abstract}
Purpose: The present investigation was undertaken to study the effect of different plasticizers on the drug delivery pattern of valsartan from tamarind gum based hydroxypropyl methylcellulose (HPMC K100) transdermal film formulation. Methods: The matrix films of valsartan were prepared by casting solvent evaporation method using triethanolamine, propylene glycol, dimethyl sulphoxide, polyethylene glycol 400 or polyethylene glycol 600 as plasticizers. Physicochemical characteristics have also been evaluated using FTIR, DSC and SEM studies. Results: Instrumental studies revealed no major drug-excipience interaction. Amorphization of drug have been noticed in all the film formulations. A significant difference of drug diffusion as well as permeation between the formulations has been observed due to the presence of different plasticizers. This study confirmed that plasticizer cotributed a major role in developing a drug delivery system in tamarind based HPMC transdermal film. Conclusion: Highest area under the curve of the drug diffusion and ex vivo permeation profiles has been assured with the PEG 600 containing film up to $24 \mathrm{~h}$ of study. Hence, transdermal film formulation could be designed using different plasticizer in tamarind based HPMC matrix system as per requirements.
\end{abstract}

Key words: Valsartan, Hydrophilic plasticizer, Tamarind gum, Transdermal film, ex-vivo permeation.

\section{INTRODUCTION}

Hydrogel forming polymers are very important excipient used in drug delivery formulations like gastro-retentive, ocular, buccal, orally dispersible and transdermal films. In transdermal delivery systems hydrogels are effectively used to deliver medicament into the body to treat chronic and/or critical ailment with lesser dosing frequency of drug. The prime advantage of this delivery system is to avoid the first pass metabolism associated with conventional drug delivery systems. In designing a transdermal film formulation plasticizers are an important class of additive which imparts a prime role in providing sufficient flexibility, comfort, softness and patient compliance. $^{1,2}$ A suitable plasticizer is required to achieve a proper consistency of the product. Plasticizers of small or large molecular weight liquids are suitably used in the film type delivery systems. ${ }^{3,4}$ The plasticizer occupies the spaces between the polymer molecules reducing the bonding forces among the polymer molecules increasing the molecular motion and the free volume. ${ }^{5}$ This mechanism depends upon the chemical composition, molecular weight and functional groups of the plasticizer polymer - systems. ${ }^{6}$

Plant derived polymers now are gaining significant applications in pharmaceutical formulations because of its large availability in the nature at lower cost. ${ }^{78}$ Recently, Tamarind gum (TG) an extracted polysaccharide from the seed endosperm of the plant, Tamarindus indica Linn. Family: Fabaceace is an upcoming natural polymer under investigation in the film formulations.
Submission Date: 29-04-2020; Revision Date: 17-07-2020; Accepted Date: 13-08-2020

DOI: 10.5530/ijper.54.3s.147 Correspondence: Prof. Subrata Mallick

Professor, Department of Pharmaceutics, School of Pharmaceutical Sciences, Siksha 'O' Anusandhan (Deemed to be University), Bhubaneswar-751003, Odisha, INDIA.

Phone: +91 9778437103 E-mail: profsmallick@gmail. com

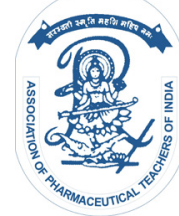

www.ijper.org 
TG is hydrophilic polysaccharide dispersible in aqueous solvent. It produces mucilaginous gels of nonNewtonian and pseudo plastic nature during swelling in aqueous solvent. ${ }^{9}$ Investigation on the role of different plasticizers Polyethylene Glycol 400 (PEG 400), Polyethylene Glycol 600 (PEG 600), dimethyl sulfoxide (DMSO), propylene glycol (PG) and triethanolamine (TEA) on the delivery of a model drug valsartan from TG (Tamarind Gum) based HPMC transdermal films was the prime purpose of the study.

\section{MATERIALS AND METHODS}

\section{Materials}

Valsartan was kindly received from Novartis, Mumbai, India and used as such. HPMC K100, Triethanolamine, Dimethyl sulfoxide, propylene glycol, polyethylene glycol 400 and polyethylene glycol 600 were purchased from Burgony Laboratories, Burbidges and Co., India.

\section{Extraction of tamarind gum (TG)}

The method tamarind gum extraction is very simple and involves few steps to carry out on a laboratory scale. Tamarind seeds collected from local market were washed thoroughly with water to remove any adhering extraneous materials. The outermost red color testa of the seeds was removed by boiling in distilled water followed by rubbing. The cleaned seeds were crushed and boiled in distilled water to get a thick viscous liquid. The liquid was passed through muslin bag and allowed to cool. Acetone was added in 1:2 ratios to precipitate the mucilage. The precipitated gum was collected and dried at temperature $50^{\circ} \mathrm{C}$ in a hot air oven. The dried gum was powdered and passed through sieve number 40 and the resulted dry powder was properly stored in airtight container for further use.

\section{Preparation of standard curve of Valsartan}

Accurately weighed $10 \mathrm{mg}$ of valsartan was dissolved in phosphate buffer solution of $\mathrm{pH} 7.4$ in a $100 \mathrm{ml}$ volumetric flask (stock). Aliquots of 0.5, 1.0, 1.5, 2.0, 2.5 $\mathrm{ml}$ were withdrawn from the stock solution to volumetric flasks of $10 \mathrm{ml}$ capacity and the volumes were made by buffer solution and mixed well to get concentration of 5, 10, 15, 20 and $25 \mu \mathrm{g} / \mathrm{ml}$. The absorbances of the resultant concentrations were analyzed at $250 \mathrm{~nm}$ as the $\lambda_{\max }$ using a UV-vis spectrophotometer (Thermo scientific, Evolution 201-uv-visible spectrometer). Absorbance vs. Concentration $(\mu \mathrm{g} / \mathrm{ml})$ was plotted and a trend line was drawn using Microsoft excel.

\section{Transdermal film preparation}

Transdermal film containing valsartan was prepared from the mixture of hydrophilic polymer hydroxypropyl methylcellulose (HPMC K100) and natural polymer tamarind (TG) by casting and solvent evaporation

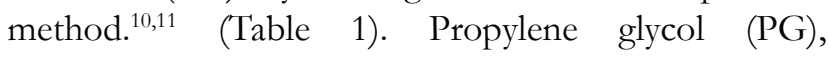
polyethylene glycol (PEG) 400 and 600, triethanolamine and dimethyl sulfoxide (DMSO) were used as plasticizers. Accurately weighed HPMC was allowed to swell in icecooled distilled water overnight. Separately, TG was dispersed in hot water and mixed thoroughly overnight to get a homogenous dispersion. TG dispersion was poured on HPMC swelled mass and stirred continuously for overnight period by magnetic stirrer. Valsartan and plasticizer were mixed and dissolved in a glass beaker with a little amount of ethanol. The previously prepared polymeric gel was transferred upon drug solution and mixed thoroughly by means of homogenization. The uniform, homogeneous product was spread evenly on a petridish and dried in a hot air oven at $40^{\circ} \mathrm{C}$ for $48 \mathrm{~h}$. The dried film was preserved in a tightly closed airtight container.

\section{Physical characterization of the films}

Digital micrometer (Mitutoyo, Japan) was used to measure the thickness of the films at different places. A specified area of patch was cut at different places and weight was taken in digital balance and the average weight was calculated. A strip of film was repeatedly folded to determine the folding endurance characteristic. ${ }^{12}$ The electrode of the $\mathrm{pH}$ meter was touched to a swelled small strip of film for one minute and the surface $\mathrm{pH}$ was recorded. Percent moisture content was determined from the difference between initial and final weight with respect to final weight. ${ }^{13}$ Accurately weighed cutting piece of film was placed inside the desiccators containing activated silica gel at the bottom at room temperature for twenty four hour or more to constant dry weight. Then the dried film piece was transferred carefully to another desiccator maintained at relative humidity of 84,74 or $79 \%$ until the weight of the film was constant to equilibrate with the inside humidity after up taking the moisture. The percentage moisture uptake was also calculated. Supersaturated aqueous solution of potassium chloride, sodium chloride and aluminium chloride were used in the desiccator to maintain 84,74 and $79 \%$ relative humidity respectively. ${ }^{14}$

\section{FTIR}

For FTIR study, pure drug Valsartan and film formulation VTFF1, VTFF2, VTFF3, VTFF4 and VTFF5 were 
measured by using Bruker infrared analyser (Bruker alpha; Ettlingen, Germany).

\section{Differential Scanning Calorimetry (DSC)}

Thermal analysis of pure drug and film were performed by differential scanning calorimetry (DSC Q10 V9.4 Build 287) to study the drug and excipients interactions. DSC analysis was carried out from 30 to $300^{\circ} \mathrm{C}$ at a rate of $10^{\circ} \mathrm{C}$ per minute under nitrogen environment.

\section{Scanning electron microscopy}

The surface morphology of the films was scanned and visualized by a Scanning electron microscope (JSM- 6390, JEOL, Tokyo, Japan) as per the machine specification.

\section{In vitro diffusion study}

Diffusion of the drug was carried by using modified Franz diffusion apparatus maintaining at $32 \pm 0.5^{\circ} \mathrm{C}$ using dialysis membrane containing $200 \mathrm{ml}$ of phosphate buffer ( $\mathrm{pH}$ 7.4) as diffusion medium. At specified time intervals samples were pipetted out and analyzed spectrophotometrically.

\section{Ex-vivo permeation study}

The drug permeation from the formulations was studied using modified franz diffusion apparatus maintained at $32 \pm 0.5^{\circ} \mathrm{C}$ taking $200 \mathrm{ml}$ of phosphate buffer $(\mathrm{pH} 7.4)$ as diffusion medium utilizing chicken skin collected from local butcher market as a test membrane. The aliquots from the diffusion medium were withdrawn at $0.5,1,2$, $3,4,5,6,7,8,24 \mathrm{~h}$ interval. The samples were analyzed after proper dilution by UV-visible spectrophotometer at $250 \mathrm{~nm}$ and the drug concentration in the sample was determined.

\section{RESULTS AND DISCUSSION}

\section{Study on the physical properties}

Results of the physicochemical properties of the films are depicted in Table 2. Uniformity in thickness (2.21 to $2.25 \mathrm{~mm}$ ) and weight of all the film (19.2 to 20.5 mg per $2 \mathrm{sq} \mathrm{cm}$ unit area) has been observed. The film produced was almost transparent and exhibited good folding endurance $(>200)$ indicating sufficiently flexible and not brittle. The surface $\mathrm{pH}$ of the film in the range of 7.12 to 7.54 indicates enough biocompatibility and is expected to show no skin irritation. The moisture absorbing capacity was increased slightly with the increase of relative humidity of 74,79 and $84 \%$. Highest moisture up taking capacity has been noticed with the film (VTFF1) containing triethanolamine plasticizer (4.15 to $6.89 \%$ ) compared to other film formulations (3.25 to $6.52 \%$ ). Small moisture content of the films at the laboratory ambient condition (2.17 to $3.45 \%$ at about $60 \% \mathrm{RH}$ ) can protect the film from microbial growth. Due to small moisture content the films are expected to be stable enough.

\begin{tabular}{|c|c|c|c|c|c|}
\hline \multicolumn{7}{|c|}{ Table 1: Formulation of transdermal film. } \\
\hline Formulation & $\begin{array}{c}\text { Valsartan } \\
(\mathbf{g})\end{array}$ & $\begin{array}{c}\text { HPMC } \\
\text { K-100(g) }\end{array}$ & $\begin{array}{c}\text { Gum } \\
\mathbf{( g )}\end{array}$ & $\begin{array}{c}\text { Plasticizer } \\
\text { used }\end{array}$ & $\begin{array}{c}\text { Plasticizer } \\
(\%)\end{array}$ \\
\hline VTFF1 & 0.8 & 2 & 0.6 & TEA & 30 \\
\hline VTFF2 & 0.8 & 2 & 0.6 & PG & 30 \\
\hline VTFF3 & 0.8 & 2 & 0.6 & DMSO & 30 \\
\hline VTFF4 & 0.8 & 2 & 0.6 & PEG 400 & 30 \\
\hline VTFF5 & 0.8 & 2 & 0.6 & PEG 600 & 30 \\
\hline
\end{tabular}

\begin{tabular}{|c|c|c|c|c|c|c|c|c|}
\hline \multirow[t]{2}{*}{ Formulation } & \multirow{2}{*}{$\begin{array}{c}\text { Weight } \\
\left(2 \mathrm{~cm}^{2}\right) \\
(\mathrm{mean} \pm \mathrm{SD}: \\
n=6) \\
\mathrm{mg}\end{array}$} & \multirow[t]{2}{*}{$\begin{array}{l}\text { Moisturecontent } \\
\text { (\%) }\end{array}$} & \multirow[t]{2}{*}{ 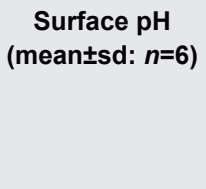 } & \multirow[t]{2}{*}{$\begin{array}{c}\text { Folding } \\
\text { endurance }\end{array}$} & \multirow[t]{2}{*}{ 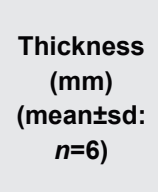 } & \multicolumn{3}{|c|}{$\begin{array}{c}\% \text { Moisture } \\
\text { uptake } \\
\text { (mean } \pm \\
\text { sd, } n=6 \text { ) }\end{array}$} \\
\hline & & & & & & RH $74 \%$ & RH $79 \%$ & RH $84 \%$ \\
\hline VTFF1 & $19.2 \pm 0.1$ & $2.17 \pm 0.66$ & $7.12 \pm 0.04$ & $>200$ & $2.25 \pm 0.015$ & $4.15 \pm 0.21$ & $5.43 \pm 0.21$ & $6.89 \pm 0.42$ \\
\hline VTFF2 & $20.5 \pm 0.1$ & $3.45 \pm 0.98$ & $7.54 \pm 0.05$ & $>200$ & $2.21 \pm 0.014$ & $3.25 \pm 0.45$ & $4.25 \pm 0.25$ & $6.20 \pm 0.56$ \\
\hline VTFF3 & $19.7 \pm 0.2$ & $3.15 \pm 0.25$ & $7.23 \pm 0.02$ & $>200$ & $2.23 \pm 0.018$ & $3.60 \pm 0.58$ & $5.62 \pm 0.15$ & $6.35 \pm 0.23$ \\
\hline VTFF4 & $20.1 \pm 0.3$ & $3.25 \pm 0.37$ & $7.48 \pm 0.08$ & $>200$ & $2.24 \pm 0.011$ & $4.01 \pm 0.42$ & $5.31 \pm 0.22$ & $6.52 \pm 0.32$ \\
\hline VTFF5 & $19.6 \pm 0.2$ & $3.33 \pm 0.44$ & $7.36 \pm 0.04$ & $>200$ & $2.24 \pm 0.015$ & $3.89 \pm 0.21$ & $4.83 \pm 0.52$ & $6.25 \pm 0.21$ \\
\hline
\end{tabular}




\section{FTIR study}

The drug valsartan contains one carboxylic group which shows two intense peaks at $3696.80 \mathrm{~cm}^{-1}$ and $2832.11 \mathrm{~cm}^{-1}$. Valsartan also consists of one pyrimidine nucleus which shows absorption peak $1596.61 \mathrm{~cm}^{-1}$. The C-H peak is shown at $1596.61 \mathrm{~cm}^{-1}$ to $12.02 .65 \mathrm{~cm}^{-1}$ due to the presence of aromatic rings (Figure 1). The aliphatic absorption peaks of $\mathrm{C}-\mathrm{H}$ are seen $765.40 \mathrm{~cm}^{-1}$ to $555.1 \mathrm{~cm}^{-1}$.

The IR spectrum of VTFF1 shows very sharp peaks at $3364.59 \mathrm{~cm}^{-1}$ and $2881.64 \mathrm{~cm}^{-1}$ due to the carboxylic residue. Also at $1647.10 \mathrm{~cm}^{-1}$ sharp peak proves the present of pyrimidine nucleus. At $1068.52 \mathrm{~cm}^{-1}$ and $1026.35 \mathrm{~cm}^{-1}$ peaks show aromatic C-H rings and presence of aliphatic $\mathrm{C}-\mathrm{H}$ group is proved due to peak at $877.27 \mathrm{~cm}^{-1}$ and $530.30 \mathrm{~cm}^{-1}$.

The spectrum of VTFF2 gives very sharp peaks at $3376.88 \mathrm{~cm}^{-1}$ and $2880.49 \mathrm{~cm}^{-1}$ due to the carboxylic residue. Also at $1643.72 \mathrm{~cm}^{-1}$ sharp peak proves the present of pyrimidine nucleus. At $1066.03 \mathrm{~cm}^{-1}$ and $1027.61 \mathrm{~cm}^{-1}$ peaks are due to aromatic $\mathrm{C}-\mathrm{H}$ rings and the presence of aliphatic $\mathrm{C}-\mathrm{H}$ group is assured by $880.83 \mathrm{~cm}^{-1}$ and $530.30 \mathrm{~cm}^{-1}$ peaks.

VTFF3 gives very sharp peaks at $3407.37 \mathrm{~cm}^{-1}$ and $2875.21 \mathrm{~cm}^{-1}$ due to the carboxylic residue. Also at $1643.83 \mathrm{~cm}^{-1}$ sharp peak proves the present of pyrimidine nucleus. At $1077.29 \mathrm{~cm}^{-1}$ peak shows aromatic C-H ring. Aliphatic C-H group is proved by $883.96 \mathrm{~cm}^{-1}$ and $528.62 \mathrm{~cm}^{-1}$ peak.

Sharp peaks at $3407.92 \mathrm{~cm}^{-1}$ and $2874.70 \mathrm{~cm}^{-1}$ are due to the carboxylic residue in VTFF4. Also at $1645.00 \mathrm{~cm}^{-1}$ sharp peak proves the presence of pyrimidine nucleus. At $1069.02 \mathrm{~cm}^{-1}$ peak indicates aromatic $\mathrm{C}-\mathrm{H}$ ring and the presence of $885.05 \mathrm{~cm}^{-1}$ and $514.26 \mathrm{~cm}^{-1}$ peaks are owing to aliphatic C-H group. The FTIR of VTFF5 gives a very sharp peak at $3403.82 \mathrm{~cm}^{-1}$ and $2874.34 \mathrm{~cm}^{-1}$ due to the carboxylic residue. Also at $1644.70 \mathrm{~cm}^{-1}$

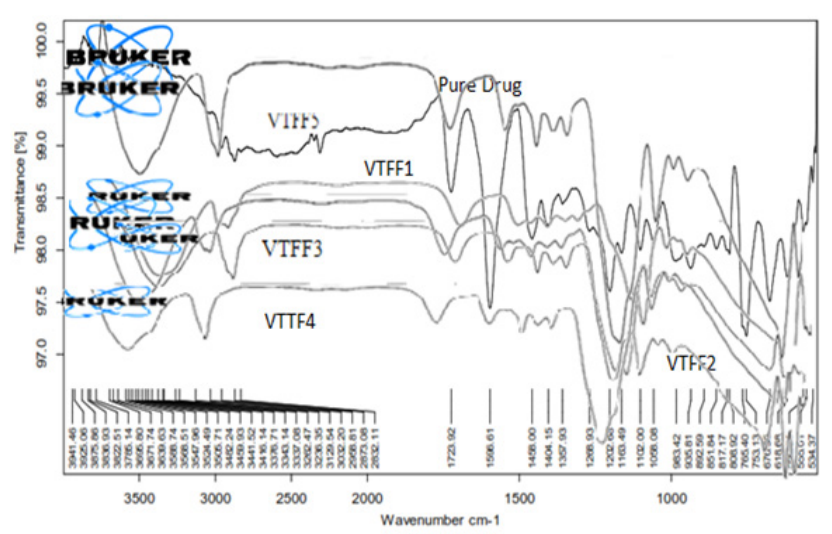

Figure 1: FTIR spectra of pure drug and formulations sharp peak proves the present of pyrimidine nucleus. At $1082.64 \mathrm{~cm}^{-1}$ and $1035.58 \mathrm{~cm}^{-1}$ peaks shows aromatic $\mathrm{C}-\mathrm{H}$ rings. The presence of aliphatic $\mathrm{C}-\mathrm{H}$ group is proved by $881.91 \mathrm{~cm}^{-1}$ and $525.44 \mathrm{~cm}^{-1}$ peaks.

The small changes in the peak shifting and intensity are the indication of amorphization of the drug in the film formulations. ${ }^{15-18}$

\section{DSC Analysis}

Thermal behavior of the pure valsartan and film formulations are illustrated in Figure 2. Pure valsartan has shown sharp endothermic peak at $98.58^{\circ} \mathrm{C}$ indicating crystalline nature. The endothermic shouldering around $50-100^{\circ} \mathrm{C}$ in the DSC thermogram signifies the dehydration process of moisture present in all the films due to the presence of HPMC. Disappearance of melting peak of valsartan in all the formulation is the indication of amorphization of the drug. Presence of plasticizer (PG), PEG, TEA and DMSO) has facilitated the transformation of crystalline drug into amorphous form in the tamarind based HPMC film. Many journal reports are published recently revealing the drug amorphization in the HPMC film formulation containing this type of plasticizers. ${ }^{19,20}$

\section{SEM Studies}

The surface morphology of the pure drug crystals (valsartan) and the film formulation are shown in Figure 3. The crystal geometry is very prominent in the photomicrograph of pure valsartan whereas, crystal morphology is almost totally disappeared in all the film formulation and even after high magnification $(10000 \times \mathrm{mag})$ it is not traceable. This result indicates the amorphous transformation of valsartan in the film. Plasticizer in the tamarind based HPMC film has brought about this amorphization. ${ }^{21}$

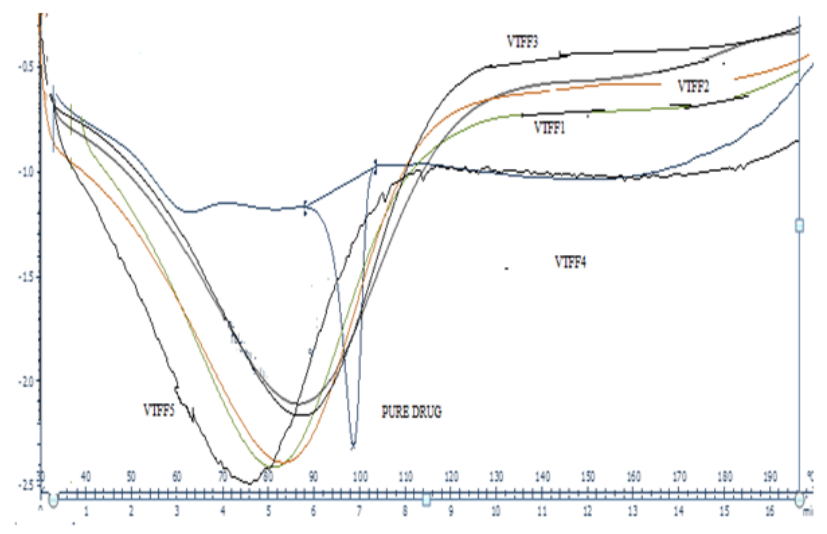

Figure 2: DSC thermo grams of Valsartan pure drug and different formulations pure drug, VTFF1, VTFF2, VTFF3, VTFF4, VTFF5 


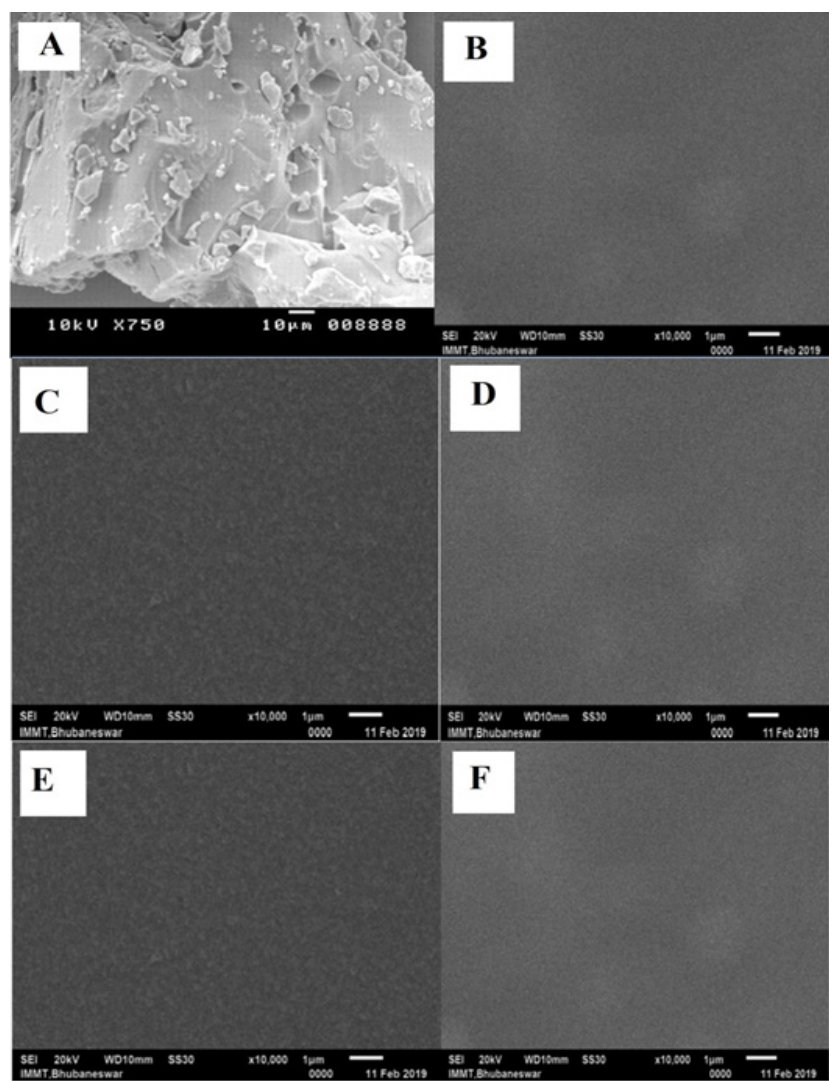

Figure 3: Surface morphology visualization of the drug and the films by scanning electron microscope (A: Pure drug, B: VTFF1, C: VTFF2, D: VTFF3, E: VTFF4, F: VTFF5)

\section{In-vitro diffusion and Ex-vivo permeation}

In vitro diffusion and ex-vivo tissue permeation profiling are important tools for predicting the drug movement in vivo. ${ }^{22}$ In vitro diffusion study was conducted in the buffered solution of $\mathrm{pH} 7.4$ and $32^{\circ} \mathrm{C}$ as the bio waiving condition for transdermal delivery. In-vitro diffusion and ex-vivo permeation ${ }^{23,24}$ profiles have been presented in Figure 4 and Figure 5. From the above plots it is revealed that the diffusion as well as permeation of drug has shown a sustained pattern and could be continued for $24 \mathrm{~h}$ or more. The drug diffusion and permeation have been varied significantly formulation wise. The presence of different plasticizer in the formulation has exhibited different influence on the above profiles. PEG 600 containing film has shown highest area under the curve both in diffusion and permeation profiles upto 24 h of study. Also PEG 400 and DMSO containing films have demonstrated higher release and skin permeation of drug compared to films prepared with PG and triethanolamine. In fact very poor permeation has been observed when PG and TEA were used (nearly $20 \%$ or more) rather than diffusion of the same (above 60 $\%$ ). Hence, change of plasticizer could be helpful in

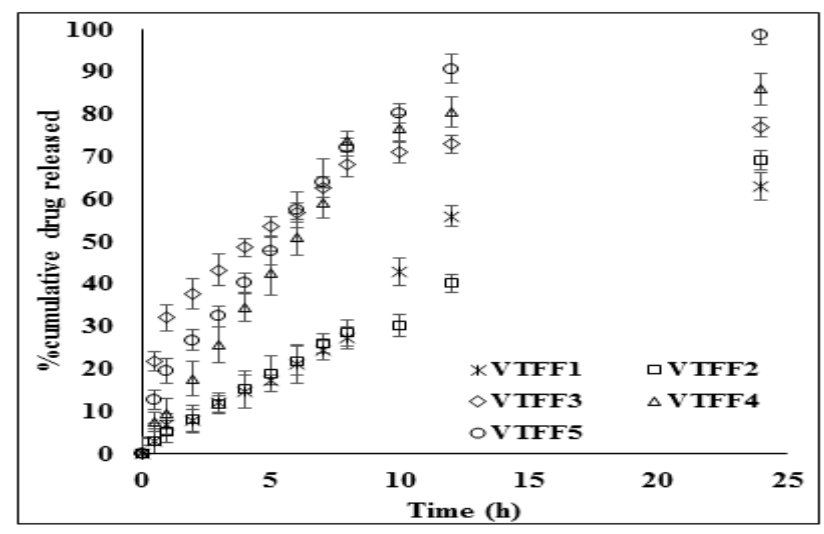

Figure 4: In-vitro diffusion of Valsartan

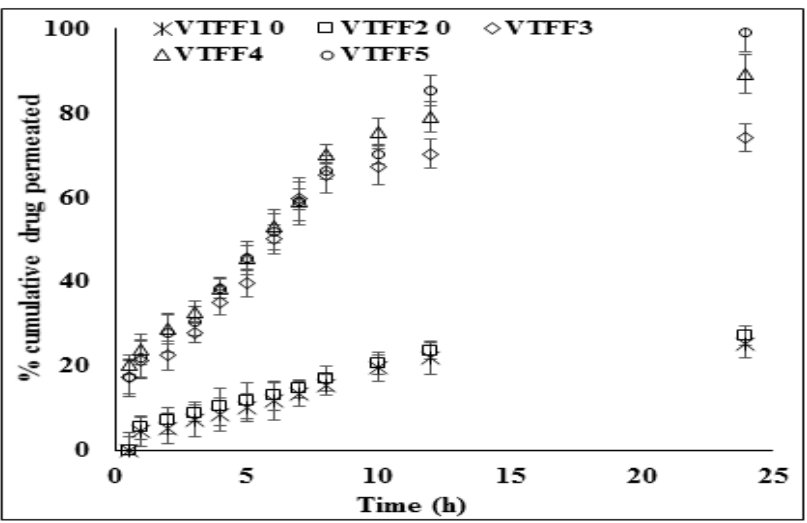

Figure 5: Ex-vivo permeation of Valsartan

designing this type of tamarind based transdermal film formulation.

\section{CONCLUSION}

Valsartan transdermal films have been prepared successfully using different plasticizers in the tamarind based HPMC matrix system. Amorphous transformation of valsartan and no major drug-excipience have been observed in all the films as confirmed from the analytical results of FTIR, DSC and SEM study. PEG 600 as plasticizer has shown highest area under the curve in drug release and skin permeation profiles upto 24 h of study. PEG 400 and DMSO in the film also have presented higher diffusion and permeation of drug compared to PG and triethanolamine containing films. Very poor permeation has been noticed when PG and TEA were used (about $20 \%$ or more) in comparison with diffusion of the same (above $60 \%$ ). Hence, tamarind based transdermal film formulation of valsartan could be designed using different plasticizer as per requirements. 


\section{ACKNOWLEDGEMENT}

The authors are indebted to Dr. Manoj Ranjan Nayak, President, Siksha 'O' Anusandhan (Deemed to be University) for supporting financial and laboratory facilities.

\section{CONFLICT OF INTEREST}

The authors have no conflict of interest.

\section{ABBREVIATIONS}

HPMC: Hydroxylpropylmethycellulose; PG: Propylene Glycol; PEG: Polyethylene glycol; FTIR: Fourier transform infrared spectroscopy; SEM: Scanning electron microscopy; DSC: Differential Scanning Calorimeter; TG: Tamarind gum.

\section{REFERENCES}

1. Sejidov FT, Mansoori Y, Goodarzi N. Esterification reaction using solid heterogeneous acid catalysts under solvent-less condition. Journal of Molecular Catalys--is A: Chemical. 2005;240(1-2):186-90.

2. Brazel CS, Rosen $S^{*}$ L. Fundamental principles of polymeric materials. John Wiley and Sons. 2012.

3. Donhowe IG, Fennema O. The effects of plasticizers on crystalline, permeability and mechanical properties of methylcellulose films. Journal of Food Processing and preservation. 1993;17(4):247-57.

4. Wilson AS. Plasticizers principles and practice. Cambrigde: The Institute of Materials. 1995.

5. Wypych G. Handbook of plasticizers. Toronto: Chem Tec Publishing. 2004;687

6. Moreno R. The role of slip additives in tape casting technology. II: Binders and plasticizers. American Ceramic Society Bulletin. 1992;71(11):1647-57.

7. Nayak AK, Pal D, Pany DR, Mohanty B. Evaluation of Spinacia oleracea L. leaves mucilage as an innovative suspending agent. Journal of Advanced Pharmaceutical Technology and Research. 2010;1(3):338.

8. Nayak AK, Pal D, Pradhan J, Ghorai T. The potential of Trigonella foenumgraecum L. seed mucilage as suspending agent. Indian J Pharm Educ Res. 2012;46:312-7.

9. Pandit AP, Waychal PD, Sayare AS, Patole VC. Carboxymethyl Tamarind Seed Kernel Polysaccharide Formulated into Pellets to Target at Colon. Indian J of Pharmaceutical Education and Research. 2018;52(3):363-73.

10. Pattnaik S, Swain K, Mallick S. Influence of polymeric system and loading dose on drug release from alfuzosin hydrochloride transdermal films. Lat Am J Pharm. 2009;28(1):62-9.

11. Pattnaik S, Kalpana S, Choudhury P, Acharya PK, Mallick S. Alfuzosin hydrochloride transdermal films: Evaluation of physicochemical, in vitro human cadaver skin permeation and thermodynamic parameters. International Braz J Urol. 2009;35(6):716-29.

12. Nafee NA, Boraie MA, Ismail FA, Mortada LM. Design and characterization of mucoadhesive buccal patches containing cetylpyridinium chloride. Acta Pharmaceutica. 2003;53(3):199-212.

13. De PK, Mallick S, Mukherjee B, Sengupta S, Pattnaik S, Chakraborty S. Optimization of In-vitro Permeation Pattern of Ketorolac Tromethamine Transdermal Patches. Iranian J Pharm Res. 2011;10(2): 193-201.

14. Nanda A, Sahoo RN, Pramanik A, Mohapatra R, Pradhan SK, Thirumurugan $A$, et al. Drug-in-mucoadhesive type film for ocular anti-inflammatory potential of amlodipine: Effect of sulphobutyl-ether-beta-cyclodextrin on permeation and molecular docking characterization. Colloids and Surfaces B: Biointerfaces. 2018;172:555-64.

15. Sahoo RN, Nanda A, Pramanik A, Nandi S, Swain R, Pradhan SK, et al. Interactions between Ibuprofen and Silicified-MCC: Characterization, Drug Release and Modeling Approaches. Acta Chimica Slovenica. 2019;66(4):92333.

16. Acharya M, Mishra S, Sahoo RN, Mallick S. Infrared spectroscopy for analysis of co-processed ibuprofen and magnesium trisilicate at milling and freeze drying. Acta Chimica Slovenica. 2017;64(1):45-54.

17. Sahoo RN, Ananya D, Kataria V, Mallick S. Solvent-free Hot Melt Extrusion Technique in Improving Mesalamine Release for Better Management of Inflammatory Bowel Disease. Indian $\mathrm{J}$ of Pharmaceutical Education and Research. 2019;53(4s):s554-62.

18. Nandi S, Mishra SA, Sahoo RN, Swain R, Mallick S. Quantitative Estimation of Tabletability of Aceclofenac after Incorporation of Titanium Dioxide using Area under the Curve. Indian J of Pharmaceutical Education and Research. 2020;54(1):68-72.

19. Pramanik A, Sahoo RN, Nanda A, Mohapatra R, Singh R, Mallick S. Ocular permeation and sustained anti-inflammatory activity of dexamethasone from kaolin nanodispersion hydrogel system. Current Eye Research. 2018;43(6):828-38.

20. Mallick S, Pradhan SK, Mohapatra R. Effects of microcrystalline cellulose based comilled powder on the compression and dissolution of ibuprofen. International Journal of Biological Macromolecules. 2013;60:148-55.

21. Dash R, Sahoo RN, Nandi S, Swain R, Mallick S. Sustained Release Bioadhesive Suppository Formulation for Systemic Delivery of Ornidazole: In-silico Docking Study. Indian J of Pharmaceutical Education and Research. 2019;53(4s):s580-6.

22. Pattnaik S, Swain K, Mallick S, Lin Z. Effect of casting solvent on crystallinity of ondansetron in transdermal films. International Journal of Pharmaceutics. 2011;406(1-2):106-10.

23. Yadav AV, Urade MN. Formulation and Evaluation of Chitosan Based Transdermal Patches of Lornoxicam for Prolonged Drug Release and to Study the Effect of Permeation Enhancer. Indian J of Pharmaceutical Education and Research. 2019;53(1):88-96.

24. Shirisha S, Joshi G, Sahoo SK, Rao YM. Preparation and Evaluation of Matrix Type Transdermal Patches of Domperidone Maleate: in vitro and ex vivo Characterization. Indian J of Pharmaceutical Education and Research. 2017;51(4):517-24. 
PICTORIAL ABSTRACT

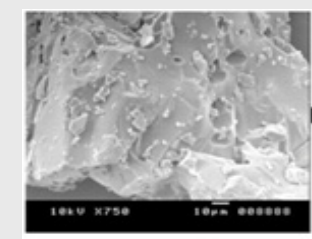

Drug crystal

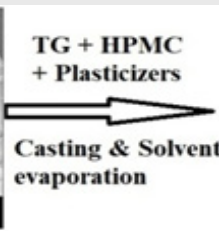
Casting \& Solv

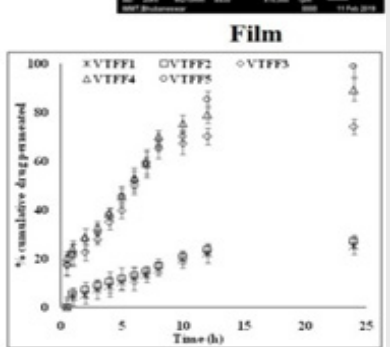

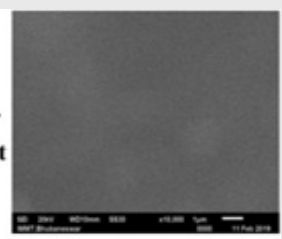

\section{SUMMARY}

- Valsartan transdermal films prepared using different plasticizers.

- Tamarind based HPMC matrix film showed amorphization of drug.

- $\quad$ PEG 600 showed highest AUC in drug release and skin permeation profiles up to $24 \mathrm{~h}$.

- Very poor permeation noticed with PG and TEA compared to their in-vitro diffusion.

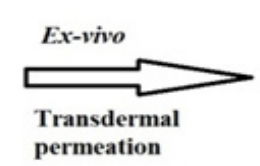

permeation

\section{About Authors}

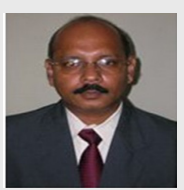

Braja Bihari Panda, M.Pharm, Ph.D, is a life member of Association of Pharmaceutical Teachers of India, The Indian Hospital Pharmacists' Association, and Odisha Chemical Society. At present he is the Associate Professor of Department of Pharmaceutical technology, School of Pharmaceutical Sciences, Siksha ' $O$ ' Anusandhan (Deemed to be University), Bhubaneswar, India. His current research areas of interest are: controlled Drug Delivery Systems using natural gum, Drug Stabilization and Kinetics, Mucosal Delivey, Powder Compaction etc.

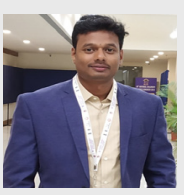

Rudra Narayan Sahoo, M.Pharm, Assistant professor at Centurion University of Technology and Management, Bhubaneswar, Odisha, India. Continuing PhD at Siksha'O' Anusandhan (Deemed to be University), Bhubaneswar, India. His research area of interest is Formulation and Development, and Drug Delivery Systems.

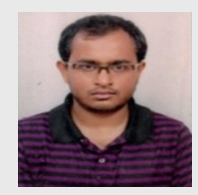

Ayan Chatterjee, M.Pharm from Siksha O Anusandhan (Deemed to University), Bhubaneswar, Odisha, India.

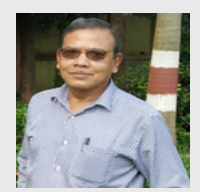

Subrata Mallick (M.Pharm, PhD, PGDBM, FIC) is a life member of Association of Pharmaceutical Teachers of India, and Indian Pharmaceutical Association. At present he is the Professor and Heading the Department of Pharmaceutics, School of Pharmaceutical Sciences, Siksha'O' Anusandhan (Deemed to be University), Bhubaneswar, India. He is the reviewer of Elsevier, Wiley, Informa Healthcare, Taylor and Francis, Bentham Science, Springer, IEEE Xplore, Dovepress etc. and editorial board member of several International Journals of America, Canada, UK, Thailand, India etc. He is also a member of doctoral committee of several universities. His current research areas of interest are: Ocular Drug Delivery Systems, Drug Stabilisation and Kinetics, Mucosal Delivey, Powder Compaction and modeling etc. More than 190 number of full research papers and conference proceedings are published in International and National levels under his guidance.

Cite this article: Panda BB, Chatterjee A, Sahoo RN, Mallick S. Effect of Plasticizer on Delivery of Valsartan from Tamarind Gel Based Transdermal Film Formulation. Indian J of Pharmaceutical Education and Research. 2020;54(3s):s485-s491. 